\section{Ahrens Receives the Hess Medal}

\section{PAGES 319, 323}

Tom Ahrens was awarded the Harry $\mathrm{H}$. Hess Medal at the AGU Fall Meeting Honor Ceremony on December 17, 1996, in San Francisco. The Hess Medal recognizes outstanding achievements in research in the constitution and evolution of Earth and its sister planets. The award citation and Ahren's response are given here.

\section{Citation}

"Tom's research career spans more than 30 years and more than 300 research papers, so it is difficult to adequately summarize his work here. It is also difficult for one person to span Tom's range of interests, so I will concentrate on Tom's shock wave contributions to our understanding of Earth. He has also done much work on understanding the effects of planetary impacts (with implications ranging from planetary accretion to cometary impacts on major planets) and much basic research in materials science. His work directly impacts (pun intended) our understanding of the origin and evolution of Mars, Moon, Jupiter, Venus, and Earth. Since the Hess medal is given for outstanding achievements on research in the constitution and evolution of Earth and its sister planets, awarding the medal to Tom seems not merely appropriate, but rather inevitable.

"For almost all of geophysical history, Tom has run academia's premier shock wave laboratory. Given the expense of such experiments, it is no small testament to Tom's unique abilities that he has kept this laboratory operating, funded, and populated with excellent graduate students and researchers. Many of Tom's early papers dealt with the fundamental understanding of the response of materials to dynamic loading as well as basic developments in shock wave technology. He extensively studied both solid and molten silicates undergoing shock loading and was the discoverer of major phase transitions in several minerals. His work on structural changes in molten silicates has profound implications for our ideas of planetary evolution. He was the first to conduct shock wave experiments on lunar samples and soon thereafter was the first to do planetary cratering calculations.

"Tom always seems to be doing several things at once, so in the early 1980 s we find him writing on the effects of large impacts

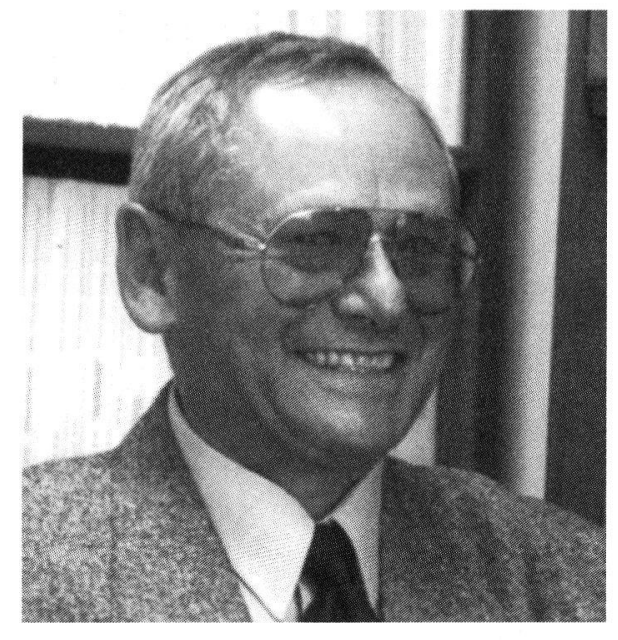

and extinctions, on shock wave-induced temperatures in silicates, on iron partitioning in the mantle, on electrical measurements in shocked minerals, on the composition of the core, on shock-induced devolatilization and the generation of planetary atmospheres, and much more.

"By the late 1980s, Tom and his coworkers had developed shock wave temperature measurement methods for opaque minerals and soon had the first direct estimates of the melting temperature of iron at core pressures. These difficult experiments gave surprisingly high temperatures for the melting of iron and were extremely controversial. By and large, these results have held up over time and have basically been verified by more extensive experiments by the government laboratories. Tom has also done many of the fundamental experiments on alloys of iron of relevance to the Earth's core that give us the information we need to talk intelligently about core composition. Tom continues to develop dynamic loading technology with experiments on preheated specimens to increase the range of pressure-temperature space sampled by the technique and with improved techniques for measuring sound velocities in shock experiments.

"While many of Tom's papers report basic equation of state data, he also uses these data to make important inferences about the Earth and the properties of minerals at high pressure and temperature. His papers with coworkers address such diverse issues as core composition, thermal expansivity of the mantle, the behavior of volatiles in planets, and sound velocities in mantle materials, and these serve to identify the next important experiments that Tom will surely be the one to do in the future.

"Well, enough of this dry detailing of a stellar academic career. What about Tom the man? After digging around, I came up with some revealing stories. It is well known that Tom has always been an extremist with regard to laboratory safety, and when you make your living blowing things up, this is not a bad idea. However, on a summer afternoon in 1970, his secretary at that time noticed an explosion had occurred close by in the neighborhood. A cloud of smoke was rising from the original (and still operating) 'lower' Kresge Seismological Laboratory! The Seismological Laboratory offices at that time were about 100 yards up the road from the lower laboratory, so Tom raced down the road to find the doors to the outside flung open with smoke pouring out of the Shock Wave Lab. A laboratory technician, David Johnson, was in the control room, shaken up but unhurt. However, the gun was in two pieces, neatly separated at the midjoint in the barrel. It was later discovered that David had mistakenly assembled the gun with 0.5 inch hardware store bolts instead of highstrength steel alloy bolts. The hardware store bolts had lasted three shots. Twenty two of the bolts had sheared off, the doors to the outside were flung open by the blast, and some 8 feet of drainpipe next to the door was flattened. The flattened drainpipe remains to this day!

"The upshot was that red lights now adorn all doors to the "new" Shock Wave Laboratory (the Roland and Helen Lindhurst Laboratory of Experimental Geophysics), and you are advised to not stand by them during experiments. Incidentally, the shot that blew the doors open (and took out two ventilators) provided good data for orthoclase, which was published in the Journal of Geophysical Research in May 1973.

"A second story concerns Tom's first attempts at "recovery" experiments in 1967. The Provost of the California Institute of Technology was concerned that the neighbors of the Kresge Seismological Laboratory who inhabited a row of mansions across from the ritzy Annandale Golf Club might have problems with large gun blasts. An acoustical consultant was hired who suggested that a test gun be fired in the proposed laboratory space while he made measurements outside. Tom went to Sears and bought a single-shot 12 -gauge shotgun for $\$ 79.95$. The test shots were barely audible outside so Tom immediately bolted the gun down and started firing at mineral samples! As sporting shotguns cannot really handle heavy plastic projectiles, several $\$ 79.95$ shotgun specials were blown up before a proper 12-gauge (now renamed $20 \mathrm{~mm}$ to be politically correct) recovery shock apparatus was machined.

"Tom has done much more than blow things up and write papers. He has worked hard for AGU, has supervised a stellar array of graduate students and postdocs, and has probably done more than almost anyone to make mineral physics the important part of AGU that it now is. It is most fitting that AGU 
now recognize Thomas J. Ahrens with the 1996 Harry H. Hess medal."-Guy Masters, Scripps Institution of Oceanography, La Jolla, Calif.

\section{Response}

"President Sean Solomon, Members and Fellows of the AGU, Ladies and Gentlemen.

"I am thrilled and honored to receive the Harry H. Hess Medal. Thank you, Guy Masters, for your kind and generous words.

"First, I want to thank my entire family for their love and support. I am also forever indebted to many wonderful collaborators, many of whom are here, as well as donors like Helen Lindhurst and the proposal reviewers over the years who have enabled my research.

"My introduction to the questions of the evolution of the Earth and planets came from the Massachusetts Institute of Technology's Patrick Hurley during my undergraduate years. I went into Earth science and planetary science because I love the Earth-its many moods on the surface, the land, and the sea. (However, its problems, unfortunately, led me into blowing up rocks in the basement.) Further inspiration came from Frank Press and Harrison Brown at the California Institute of Technology where I was first a graduate student.

"During the following year, while I was fulfilling my ROTC commitment as an Army Second Lieutenant at Aberdeen Proving Ground, Maryland, I had the good fortune to be assigned to work on the problem of the ground shock vulnerability of the NIKE Air Defense system. The Army was starting to put these missiles underground in bunkers. I learned that you could describe the dynamic properties of rocks by measuring the kinematics of shock wave propagation.

"At the close of my Army tour I was fortunate to be taken on as a graduate research assistant by Samuel Katz at Rensselaer Polytechnic Institute. Sam Katz was a student of Maurice Ewing at Lamont-Doherty Geological Observatory. After Lamont, he went to work for a geophysicist, Thomas Poulter, who was an Antarctic explorer and an expert on the geophysical applications of high explosives, at Poulter's laboratories at Stan- ford Research Institute (SRI). Sam Katz had just come to Rensselaer from Poulter Laboratory at SRI, where this group was pioneering the application of explosively induced shock waves to measure the dynamic compression of metals. In 1962, after receiving a Ph.D. from Rennselaer, I went to work at Poulter Laboratory myself, and began to use high explosives to study the properties of rocks and minerals. My first paper on Shock Compression of Crustal rocks, coauthored with Victor Gregson Jr., appeared in the Journal of Geophysical Research in 1964. This was exciting, hands-on research. I came home at night with my ears still ringing from the day's explosions and with TNT under my fingernails

"I began to realize that the high-pressure dynamic properties of Earth materials could be applied to understanding both the physics of planetary interiors and impact processes. At that time, our primary interest was on impact cratering on the Moon. President Kennedy had just announced the United States' intention to race the Soviet Union to the Moon.

"However, in July 1965 the Mariner 4 spacecraft sent man's first images of Mars' surface to Earth, and to my, and many others' surprise, the surface of Mars was also heavily impact-cratered. Thus planetary surfaces, other than the Moon, were also cratered.

"I decided to pursue the study of shock effects in minerals, in part to understand the effects that Eugene Shoemaker, recipient of the 1996 Bowie Medal, was studying.

"The high-pressure, rutile-structured polymorph of quartz had just been synthesized in Moscow by Sergei Stishov, who was then a graduate student. A few months later, Ed Chao, Eugene Shoemaker, and coworkers dis covered this phase at Meteor Crater, Arizona and named it stishovite. This was the first silicate mineral in which oxygen was in octahedral coordination with silicon-a precursor to unraveling the mineralogy of the lower mantle. I realized that the properties of highpressure phases of minerals could be studied using shockwave data. I applied to NASA for support and began research on shock compression of minerals. It was only in 1972 , when I went to my first Conference at the Lunar and Planetary Institute, that I realized the role Princeton's Harry Hess had played in es- tablishing NASA's Planetary Exploration Program-a program that has benefitted the research of many in this room.

"In 1967, Caltech was seeking a junior faculty member who was interested in relating seismic velocity to depth profiles, like those Don Anderson and his students were measuring, to determine their relationship to highpressure mineralogy and temperature. Several months after a tongue-in-cheek discussion with Frank Press, who was then Chairman of Geology and Geophysics at MIT, as to whether one could mount a big gun vertically onto the tall skinny MIT Green Building, Caltech appointed me to the geophysics faculty. This has been a superb highly supportive environment in which to conduct research and teach.

"At that time, the Caltech geophysics group was mainly located in the Seismological Laboratory. The Seismology Lab offices were housed on a spacious mansion in the San Rafael Hills, 5 miles west of campus in an exclusive neighborhood adjacent to the Annandale Country Club. As Guy Masters explained, this did not appear to be a good place to conduct high-explosive experiments!

"As many in the audience know, the adjacent seismographs, surprisingly, never detected our high-frequency gun-launched shock experiments. Moreover, I began to work with a number of talented and innovative graduate students and, later, postdoctoral fellows and visitors, who taught me many things.

"Later, Gene Shoemaker introduced me to Helen Lindhurst, who provided funds for the Lindhurst Laboratory of Experimental Geophysics in the Geophysics and Planetary Science Building at Caltech.

"I will stop at this point to also thank the dedicated technical and administrative staff and leaders of Caltech over the years, as well as the graduate students, postdoctoral fellows, and visiting associates with whom I have so far collaborated both at Caltech and elsewhere.

"It gives me great pleasure to receive AGU's Harry H. Hess Medal.

"Thank you very much."-Thomas $J$. Ahrens, California Institute of Technology, Pasadena

\section{In Brief}

\section{PAGE 318}

Watch the creep! The 1989 Loma Prieta earthquake that shook California helped to delay large earthquakes near San Francisco by relaxing stress on the Hayward fault, the most hazardous fault zone in the San Francisco Bay region. After the magnitude 7.0 Loma Prieta earthquake, creep rates for the Hayward fault, a major branch of the San An- dreas fault system, declined significantly. However, in 1996, a large increase in the creep rate in the Hayward fault was observed by James Lienkaemper of the U.S. Geological Survey and colleagues, who reported their findings in the June 27 issue of Science.

Prior to 1989, average creep rates within the Hayward fault remained steady at about $5 \mathrm{~mm} / \mathrm{yr}$. After the Loma Prieta earthquake, they were severely reduced until 1996, when the fault exhibited the largest rate of downward movement ever measured. During the 63 days between two geological surveys, 18 mm of creep occurred. The authors modeled changes in the regional stress field produced by the Loma Prieta earthquake and concluded that monitoring changes in creep rates could alert scientists to future changes in stress that are large enough to influence the timing of major earthquakes.

Scanning skies and ocean On July 19, the new NOAA oceanographic research vessel, the Ronald H. Brown, was commissioned by Department of Commerce Secretary William M. Daley in Charleston, S.C. The 274-foot ship was named after the late former Commerce 